\title{
Differences in cardiac involvement between carriers of Duchenne and Becker muscular dystrophy - a cardiovascular magnetic resonance study
}

\author{
Anca R Florian ${ }^{1 *}$, Anna Ludwig², Sabine Rösch², Udo Sechtem², Ali Yilmaz ${ }^{1}$ \\ From 18th Annual SCMR Scientific Sessions \\ Nice, France. 4-7 February 2015
}

\section{Background}

Duchenne (DMD) and Becker (BMD) muscular dystrophies are X-linked recessive disorders associated with both skeletal myopathy and progressive cardiomyopathy in males. Although BMD patients present milder skeletal muscle involvement, they have been shown to present more advanced cardiomyopathy than DMD. Female DMD/BMD carriers are usually free of skeletal muscle symptoms but they may also develop cardiomyopathy.

The present study aimed at characterizing the presence and pattern of cardiac abnormalities in a group of genetically-proven MD-carriers by means of comprehensive CMR studies. Moreover, we wanted to test whether DMD carriers (DMDc) and BMD carriers (BMDc) are differently affected.

\section{Methods}

Thirty-six (age 44 \pm 14 yrs) female MD-carriers (20 DMDc and $16 \mathrm{BMDc}$ ) were prospectively enrolled. All patients underwent a multi-parametric CMR study comprising cine- and LGE-CMR (1.5-Tesla). A left ventricular (LV) LV ejection fraction (LV-EF) $<55 \%$ and/or presence of LGE defined a pathologic CMR study.

\section{Results}

In the total study group, mean LV-EF was $64 \pm 9 \%$. Seventeen $(47 \%)$ patients had at least one pathological CMR finding based on the CMR results: 6 (17\%) patients demonstrated (at least) a reduced LV-EF and 16 (44\%) patients showed (at least) presence of LGE. All
LGE positive patients $(\mathrm{N}=16)$ showed non-ischemic LGE with subepicardial involvement of the LV lateral wall as most frequent pattern $(13 / 16,81 \%)$. Compared to BMDc, DMDc were significantly younger $(40 \pm 11$ yrs vs. $50 \pm 16 \mathrm{yrs}, \mathrm{p}=0.038$ ) and presented significantly higher $\mathrm{LV}$ end-systolic volumes $(53 \pm 18 \mathrm{~mL} / \mathrm{m} 2$ vs. $40 \pm 13 \mathrm{~mL} /$ $\mathrm{m} 2, \mathrm{p}=0.025)$ in addition to lower LV-EF $(62 \pm 8 \%$ vs. 68 $\pm 9 \%, \mathrm{p}=0.039)$. Among DMDc, $65 \%(\mathrm{~N}=13)$ showed presence of LGE compared to only $19 \%(\mathrm{~N}=3)$ in BMDc $(\mathrm{p}=0.008)$. Taken together, a pathologic CMR result was found in $65 \%(\mathrm{~N}=13)$ of DMDc compared to only $25 \%$ $(\mathrm{N}=4)$ in BMDc $(\mathrm{p}=0.023)$.

\section{Conclusions}

Cardiac involvement is a frequent finding in female carriers of DMD, but rarely observed in carriers of BMD. Both, DMDc and BMDc with cardiac involvement demonstrate the same myocardial fibrosis pattern as their male counterparts with overt disease. Interestingly, in contrast to what is seen in male patients with DMD and BMD, female carriers of DMD present with a more advanced cardiomyopathy than carriers of BMD.

\section{Funding}

None.

\section{Authors' details \\ ${ }^{1}$ Cardiology, Uniklinikum Muenster, Muenster, Germany. ${ }^{2}$ Cardiology, Robert Bosch Hospital, Stuttgart, Germany.}

Published: 3 February 2015

${ }^{1}$ Cardiology, Uniklinikum Muenster, Muenster, Germany

Full list of author information is available at the end of the article 
doi:10.1186/1532-429X-17-S1-Q90

Cite this article as: Florian et al:: Differences in cardiac involvement between carriers of Duchenne and Becker muscular dystrophy - a cardiovascular magnetic resonance study. Journal of Cardiovascular Magnetic Resonance 2015 17(Suppl 1):Q90.

Submit your next manuscript to BioMed Central and take full advantage of:

- Convenient online submission

- Thorough peer review

- No space constraints or color figure charges

- Immediate publication on acceptance

- Inclusion in PubMed, CAS, Scopus and Google Scholar

- Research which is freely available for redistribution

Submit your manuscript at www.biomedcentral.com/submit 